\title{
The Topic of the School Building in the Milanese Professionalism
}

\author{
Michele Caja, Martina Landsberger and Angelo Lorenzi
}

\begin{abstract}
The question of the relationship between modern architecture and civil themes and of technological experimentation takes on a central role in the school building projects in which, between the 1950s and 1960s, Arrigo Arrighetti, Roberto Menghi and Ignazio Gardella, among others, are involved. The Milanese architects often addressed the issue in the absence of a definite place of intervention and work mainly on flexible systems, adopting the pavilion as the main element of the construction, that allow adaptations, expansions and transformations of the functional program. They experienced innovative technological solutions, such as the prevalent use of prefabricated elements, light metal structures, technological details derived from industrial plants.
\end{abstract}

Keywords School • Typology • Construction • Roberto Menghi • Ignazio Gardella

In the 1950s, though still struggling with the aftermath of World War II (WWII), Milan was a very lively, creative, open and cosmopolitan city, willing to regain the European and international role it had lost during the fascist era. Nevertheless, in those years, Milan was inhabited by an extraordinary generation of intellectuals, artists and architects: the BBPR group, Franco Albini, Luigi Caccia Dominioni, Mario Asnago, Claudio Vender, Roberto Menghi and Ignazio Gardella, just to mention the best known, animated the Milanese architectural scene with punctual interventions, that were able to define new themes and urban intervention principles, even if they did not change the overall urban structure. These themes will have a great fortune in the following years and they are still at the very core of Italian and European architectural design researches (Bottoni 1954).

Housing and dwelling for the urban bourgeoisie were the main topic with which this generation of architects, attentive to European experiences, dealt. However, also the design of public buildings has a great importance within their researches. Through

M. Caja (西) · M. Landsberger · A. Lorenzi

Architecture, Built Environment and Construction Engineering-ABC Department,

Politecnico di Milano, Milan, Italy

e-mail:michele.caja@polimi.it 
his many articles and essays written in the aftermath of WWII, Giulio Carlo Argan, one of the most important Italian architectural historians of the twentieth century, pointed out the museum as a central theme to work on in order to restore dignity and urban quality to those cities that, along with their built heritage, risked losing their identity and historical memory (Argan 1949). In those years, the museum became one of the privileged places for rebirth, a gymnasium for up-to-date museological installations, a challenge to the communicative possibilities of art, a testimony of wide-ranging cultural projects. Moreover the school as a design research theme had a different and more controversial role in Italian culture after World War II. Previously, teaching institutions had assumed a central importance in the context of the fascist reforms. The Gentile Reform of 1923 and the Reform of 1926, through the establishment of the Opera Nazionale Balilla, opened a broad program of civic and physical education for young people. The centrality of classical culture and its contradictory identification with the fascist ideals on the one hand, and the importance of physical education as an element that introduces military discipline on the other hand, are the background of a project of control, propaganda and overall orientation of the young people, future Italian citizens. Obviously, this program included extensive investments also for the construction of schools and scholastic institutions, which represented the testing ground for the Italian architects of the time.

Republican Italy, asserted in June 1946, will struggle for a long time before defining a clear project for the reform of educational institutions. The Gentile Reform remains for a long time one of the benchmarks in the field of education to which the 1947 Constitution adds principles of spreading culture and opening opportunities to the weakest social classes. The main intervention in the teaching sector will take place with the reform of 1962 which introduces the extension to a minimum of 8 years of school education and, above all, establishes a unique system of middle school, eliminating the distinction between professional schools and secondary education, to respond to the needs of a democratic society that wants to offer training opportunities to all citizens. With the birth of the new middle school, education started to be a mass phenomenon, with important and problematic consequences that concern the school buildings in the country. This less known aspect of the research of Milanese professionalism seems to be important to investigate because, in the absence of a clear design on the part of the institutions, architectural culture takes charge of proposing innovative settlement, up-to-date typological and constructive solutions. The question of the relationship between modern architecture and civil themes and of technological experimentation take on a central role in the school building projects in which, between the 1950s and 1960s, Arrigo Arrighetti, Roberto Menghi and Ignazio Gardella, among others, are involved (Menghi 2000; Porta 1985; Samonà 1981). The Milanese architects often addressed the issue in the absence of a definite place of intervention and work mainly on flexible systems, adopting the pavilion as the main element of the construction, that allow adaptations, expansions and transformations of the functional program. They experienced innovative technological solutions, such as the prevalent use of prefabricated elements, light metal structures, technological details derived from industrial plants. They often adopted 
indirect lighting systems that were not yet used in Italy but were being exploited in Northern Europe.

The text we present is part of a broader research project started in 2016 in collaboration with some professors, researchers and PhD students of the Politecnico di Milano - in particular the ABC Department and the Design Department-and the Università di Parma-Department of Engineering and Architecture-with the CSAC/Centro Studi e Archivio delle Comunicazioni of the Università di Parma. The work involves a group of young researchers and doctoral students coming from different disciplinary fields, and it is based on the extraordinary archives of drawings, photographs and documents on twentieth-century Italian architecture, conserved at the CSAC. The CSAC, founded by Arturo Carlo Quintavalle, preserves original materials related to the field of visual communication, artistic research and Italian design culture and, today, is one of the most important Italian archives on modern architecture.

Recently, the research has focused on Roberto Menghi, Ignazio Gardella and Luigi Vietti, with the aim of reopening, starting from the reading of the works to archive documents, the critical debate on the work of these masters of Italian architecture by suggesting new and different points of view, and, at the same time, in order to investigate the less known and often unpublished works by these architects. During its development, the research has also been carried out in strict relationship with other institutions, museums and research organizations.

\section{Roberto Menghi: Pirelli Foundation and French High School}

The research of Roberto Menghi's school building reflects typical aspects of architectural and urban culture practiced since the post-war period, although it still dates back to the principles and ideas of cities developed by the Modern Movement. Both projects analyzed here are buildings that have a weak, if not non-existent, relationship with the city: on the one hand, precisely because of their location within non-consolidated contexts, in areas of new expansion or with a thin and not compact urban fabric; on the other hand, for the way in which the buildings are conceived as autonomous objects, with an inner articulation, but without a precise relationship with the surrounding streets. In both cases these are buildings organized in single pavilions placed inside the block and set back from the lot's boundaries. This solution, typical of many schools built between the 1950s and 1970s, not only in Milan, stems from the idea of considering the school as a special building, collective equipment, linked to an idea of the city subdivided into functional sectors-such as the term often still used today "school complex" means-to create autonomous mono-functional parts, often unrelated to the surrounding existing urban fabric. This idea of the plexus, which on a larger scale becomes a campus, remains a subject to be addressed critically today when we are faced with the theme of the school 
building, to avoid understanding it as if it were an independent organism, foreign to the surrounding context. Something that did not happen in the nineteenth-century school typology-from the Schools of Camillo Boito (1836-1914) to those of the first decades of the twentieth century - in which the building was always included within the morphological constraints posed by the city, such as the relationship with the street, the inclusion in a building curtain and an urban block, the adjacency with residential houses and buildings for other uses, the entrance hall and the courtyard, open to the road or closed, as a collective element, the multi-storey development as a height articulation system.

The choice, precisely, to untie the school building from any urban constraint, the often isolated location within a lot, the decomposition of the organism into a system of isolated pavilions, the introduction of a reduced height of maximum 2-3 floors, the disappearance mostly of the central aggregative space of the court are all aspects that distinguish, mostly, the research on the school building intended as an autonomous specialized typology, up to the present day.

In the architectural production of Roberto Menghi the school building represents a little-frequented theme, which he tackled essentially on two occasions. The first is the project for a training centre for the Pirelli Foundation in Viale Fulvio Testi in Milan (1957-1958), which still exists today despite of variations within it. The second is a more complex project, for the headquarters of the French Lyceum of the Chamber of Commerce, which is developed on two different sites between the years 1958 and 1960-1961. The first project is located at Villa Simonetta in via Stilicone in Milan, one of the most interesting examples of Renaissance architecture in Lombardy, and the second one on an urban block along via Laveno in the outer district of San Siro, where it was partly built (now demolished and replaced by another building housing the Lycée Stendhal).

Despite the diversity of the functional program of the two projects, the theme is developed according to the type of the isolated pavilion, connected by low connecting bodies. In the Pirelli Foundation the two parallel pavilions of different section and heights, respectively, contain the large floor-to-ceiling space of the workshops and the volume of the classrooms, with the adjoining canteen. Connected by a transverse entrance body, with wardrobe, they build an open C-system on Viale Fulvio Testi. The brick construction is completed by a roof structure defined by an articulated section with large metal trusses and windows. If the industrial character and the constructive choices are the most interesting aspects of this building, the project for the French Lyceum touches on different aspects, concerning the urban scale, the research on the scholastic typology, the relationship with the pre-existences, and the different variants of the project.

There are several variants for the proposal on the site of Villa Simonetta; of the first version proposed by Menghi (January 1958) emerges in particular its radical nature - still indebted to the logic of the tabula rasa of the Modern Movement, but also strangely deaf to the topic of environmental pre-existences already theorized at the time by Ernesto N. Rogers - with which he proposes to completely replace Villa Simonetta, except for the porch, which is moved and reassembled along the street. In this case the building has a close relationship with the street, but at the expense 
Fig. 1 French High School, Milan: proposals for Villa Simonetta site, Milano, 1958, Layout study for the French High School, Mezzanine and first floor plan, January 1958, ink and pencil on tracing paper, $\mathrm{mm}$. 624 X 440, 1:500. (CSAC, Sezione Progetto, Fondo R. Menghi B034577S)

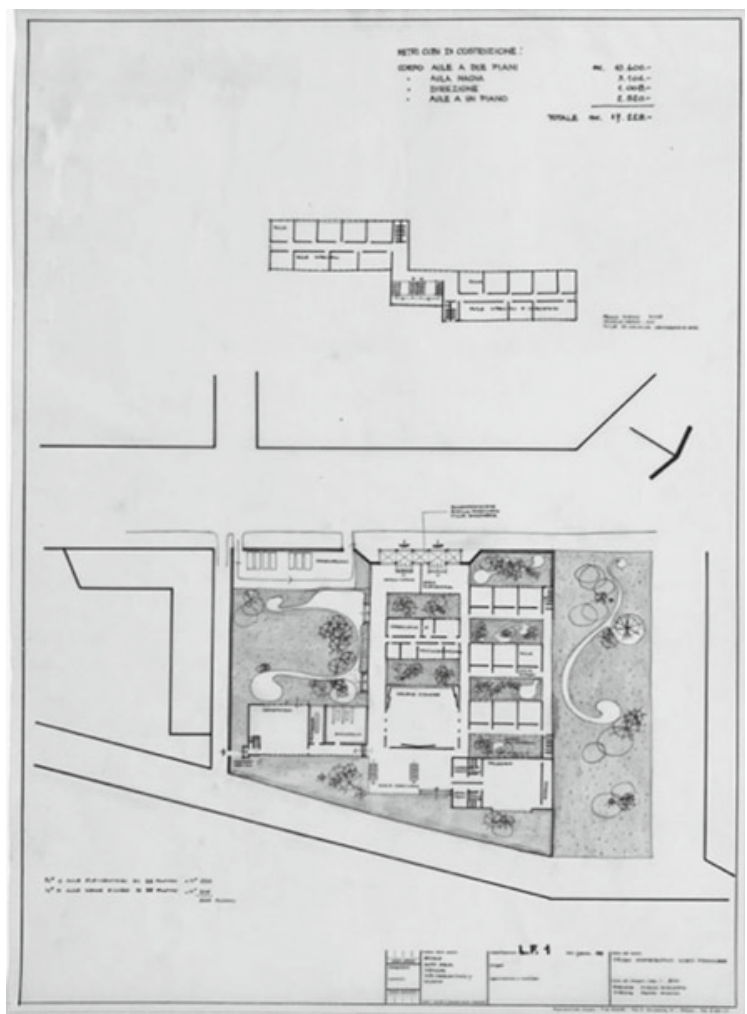

of the overall removal of the historic building. From the relocated portico, a double corridor distribution system develops around a central courtyard, partially occupied by the transverse bodies of the management offices and the aula magna.

On the external sides of this double distribution system, on the left side, is the access to the three bodies of the classrooms, based on a comb-structure, and on the right side of a single terminal body, containing the library and the refectory. That this circulatory system split around a central inner space, with lateral combed bodies (which indirectly refers to the layout of the Elementary School of Fagnano Olona built by Aldo Rossi 15 years later) was congenial to Menghi, it will also be seen in the solutions designed for the second site. A particular solution when compared with the other elaborate variants, which not only preserve the layout of the villa but assume it as a compositional and ordering center for the various additional extension bodies. Instead of replacing the ancient monument, two undated solutions widen the villa toward the street side, extending the main building on the right side or the left side, respectively, and re-proposing the $\mathrm{C}$-shaped portico on the inner side of the court. This hypothesis for the courtyard portico will be resumed in another solution (March 1958), where the fourth side will be occupied by two symmetrical buildings, with a central access passage to the rear garden, containing the refectory and the 
Fig. 2 French High School, Milan: proposals for Villa Simonetta site, Milano, 1958, Layout study for the French High School, ground floor, first floor and second floor plans 7.3.58, ink and pencil on tracing paper, mm.618X447, 1:500. (CSAC, Sezione Progetto, Fondo R. Menghi B034576S)

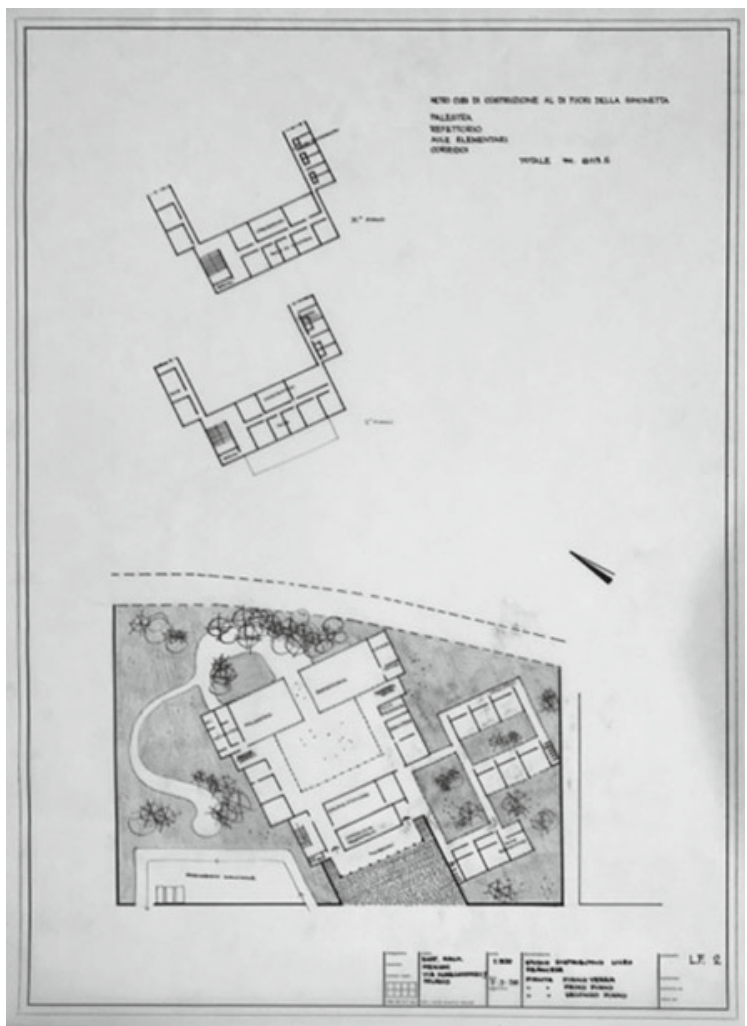

library, while on the right side a corridor system is developed around another court to distribute the one-storey bodies of the classrooms (Figs. 1 and 2).

The layout of the first solution reappears later in the subsequent location, developed on an elongated rectangular lot along the via Laveno in San Siro. There are also several versions of this project, starting from the common layout, founded on a system of pavilions parallel to the road and connected to each other by one-storey distribution bodies, which form a single connecting plate (Fig. 3).

\section{Ignazio Gardella: Prefabricated School Projects}

As we have seen earlier, the topic of the school offers the designer a double opportunity: first of all, an interpretative possibility in which the typological aspect becomes a fundamental element in the development of the character of the project. A second opportunity, instead, refers to the question of experimentation, to the possibility of working, for example, with prefabricated elements useful to speed up the construction and, above all, to reduce costs. In the post-war period in which Italy must 

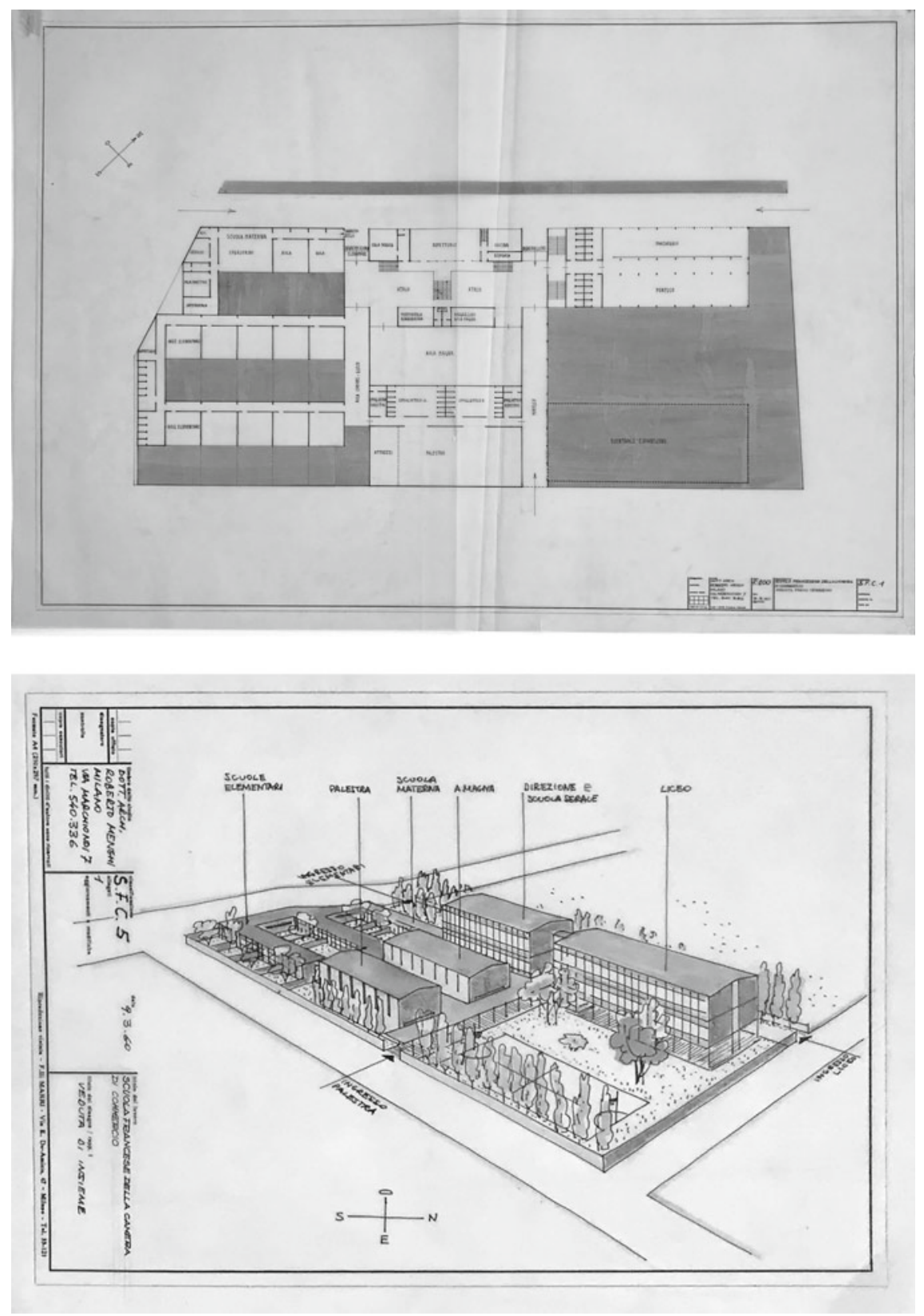

Fig. 3 French High School, Milan: proposals for Villa Simonetta site, Milano, 1960-61, Overall view, Axonometry, marker and ink on tracing paper, mm. 240X325. (CSAC, Sezione Progetto, Fondo R. Menghi, B034580S); ground floor plan, 9.03.1960, ink and halftone screen on tracing paper, 1:200. (CSAC, Sezione Progetto, Fondo R. Menghi, B034581S) 
substantially rebuild itself "in toto", both from the material point of view-such as buildings - and the more properly "spiritual" one providing a new education to the population, the issue of the school becomes one of the fields on which architects' work converges.

In Milan, for example, from 1950s until 1970, Arrigo Arrighetti (Bodino 1990), ${ }^{1}$ director of the Technical Office first, and later of the Urban Planning Office, represents an interesting figure of designer engaged in the search for a new form of public buildings conceived as decisive elements for reconstructing the identity of the city and its representation and recognition in the society. In this sense, the projects of Arrighetti's schools, in their desire to build the relationship with the places in which they are placed, offer a different point of view from that of Roberto Menghi and Ignazio Gardella.

The CSAC archive, which brings together the entire work of Gardella, ${ }^{2}$ preserves three school's projects: the design for the elementary school of Nerviano (1946), a design-competition for the construction of a school with the AUCTOR system (1965) and the one for a nursery school in Milan (1964). Only the oldest project for Nerviano presents an urban dimension. The other two projects seem so detached from the city that Gardella himself, almost as if he felt the need to verify its urban role, draws a perspective of the building inserting it in a totally "invented" context to evoke the idea of the city.

While the city does not seem to exist, so that the project is almost totally selfreferential, it is instead true that all the three Gardella's projects provide evidence to a careful research on the topic of school typology. The school for Gardella, therefore, is a place built on the relationship that the collective space where all the students can meet together (garden, courtyard, gymnasium, etc.) establishes with the system of classrooms. It is interesting, for example, to look at the project dating back to 1965 in its various stages of study. The starting point is a simple system in which the two buildings of the classrooms are arranged in line, parallel to each other, connected to each other by the gym. In this way a C-shaped composition is defined with a central collective space. This first solution-documented by a series of sketches and distribution schemes - is almost immediately abandoned in favor of a composition that, as already seen in Roberto Menghi's projects, tries to break down the building into its parts determining a composition in which separated pavilions enter into relationship through a system of paths. In this solution, which involves moving the gym to one side and therefore a first disarticulation of the initial composition, the theme of the $\mathrm{C}$ of the classrooms in relation to the central space remains stable (Fig. 4).

The drawings dated November $1965,{ }^{3}$ instead present a very different solution from the typological point of view; the desire to identify the idea of the school

\footnotetext{
${ }^{1}$ Arrigo Arrighetti (1922-1989. The book edited by C. Bodino represents the only document that witnesses his work. Few are indeed the critical essays that have taken his figure into consideration. ${ }^{2}$ For this occasion the project for the University of Genoa was deliberately omitted. We believe that it represents a different case because of its scale and for its diversity in approaching to the issue.

${ }^{3}$ It is assumed that this is the final solution. The previous solutions do not report any dating.
} 

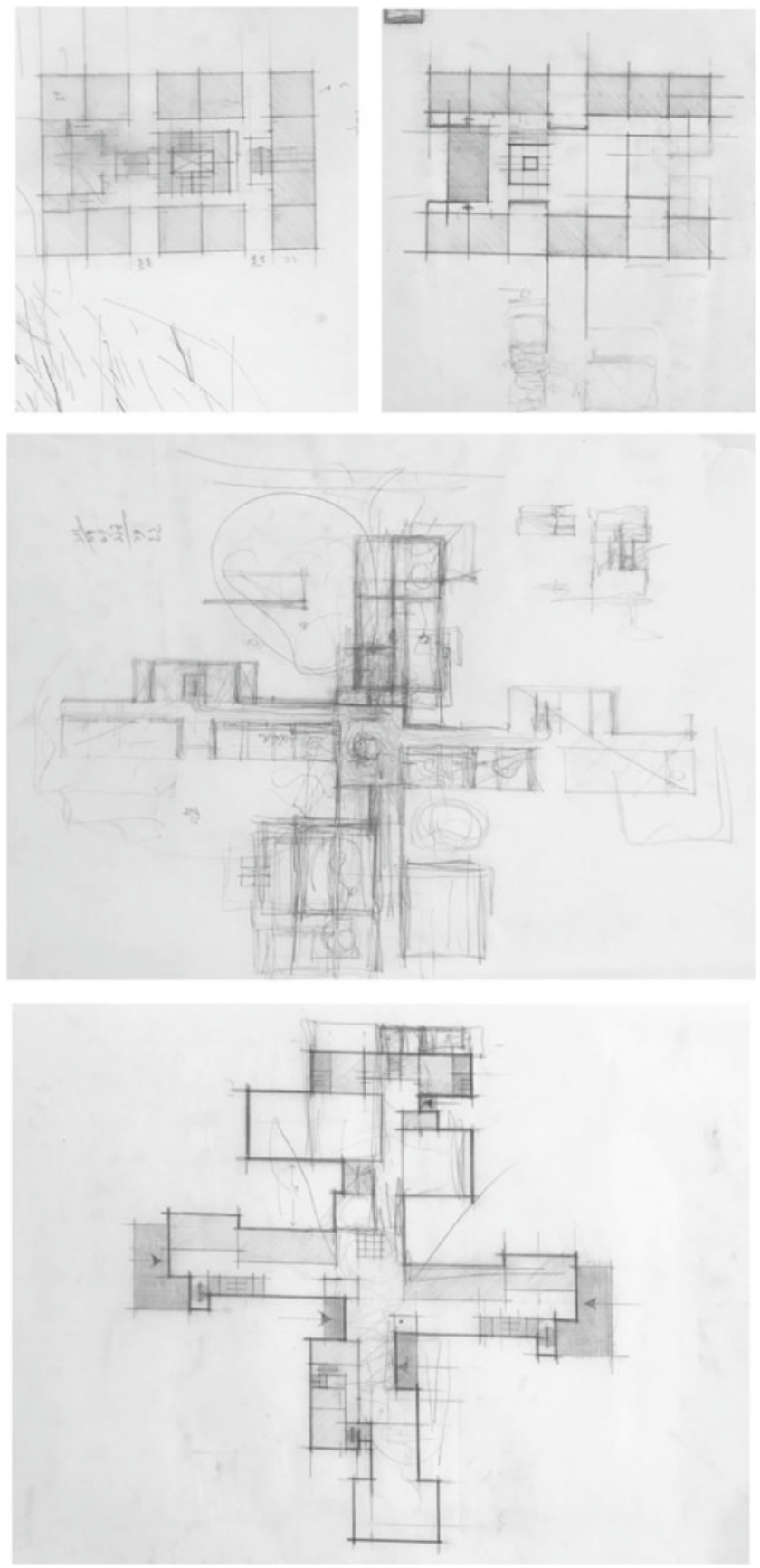

Fig. 4 Prefabricated Schools for the Municipality (Competition Contract), via Manin, Varese, 1965. Study Sketches, pencil on tracing paper. (CSAC, Sezione Progetto, Fondo I. Gardella, B001612P) 
through the definition of a space able to represent the idea of the community persists. In this solution Gardella moves from a first cross-shaped scheme with a large common space placed in the intersection of the four arms of the cross. Subsequently, Gardella draws a more complex system in which the cross remains losing an arm. This is the solution that Gardella tries to verify in the perspective mentioned above.

The school is conceived as a large building articulated on three floors and built back from the street line.

On the ground floor, in the three arms of the cross, the collective spaces such as special classrooms and laboratories, and the gymnasium are overlooking the equipped back garden or the green space that separates the school from the road. A large atrium, at the intersection of the three arms, marks the entrance to the school and contains the vertical distribution system. The classrooms are located on the upper floors (Fig. 5).

Similar characteristics can be found in the project for a nursery school in Milan. In this case the type is represented through the construction of a large central space useful to collect all the children and in the definition of a sort of enclosure consisting of the blocks of the classrooms.

In this project each volume of the classroom contains in itself also a space destined to "refectory". Between the volumes there is a glazed partition system creating the relationship with the outside and defining the lighting system of the large central courtyard (Fig. 6).

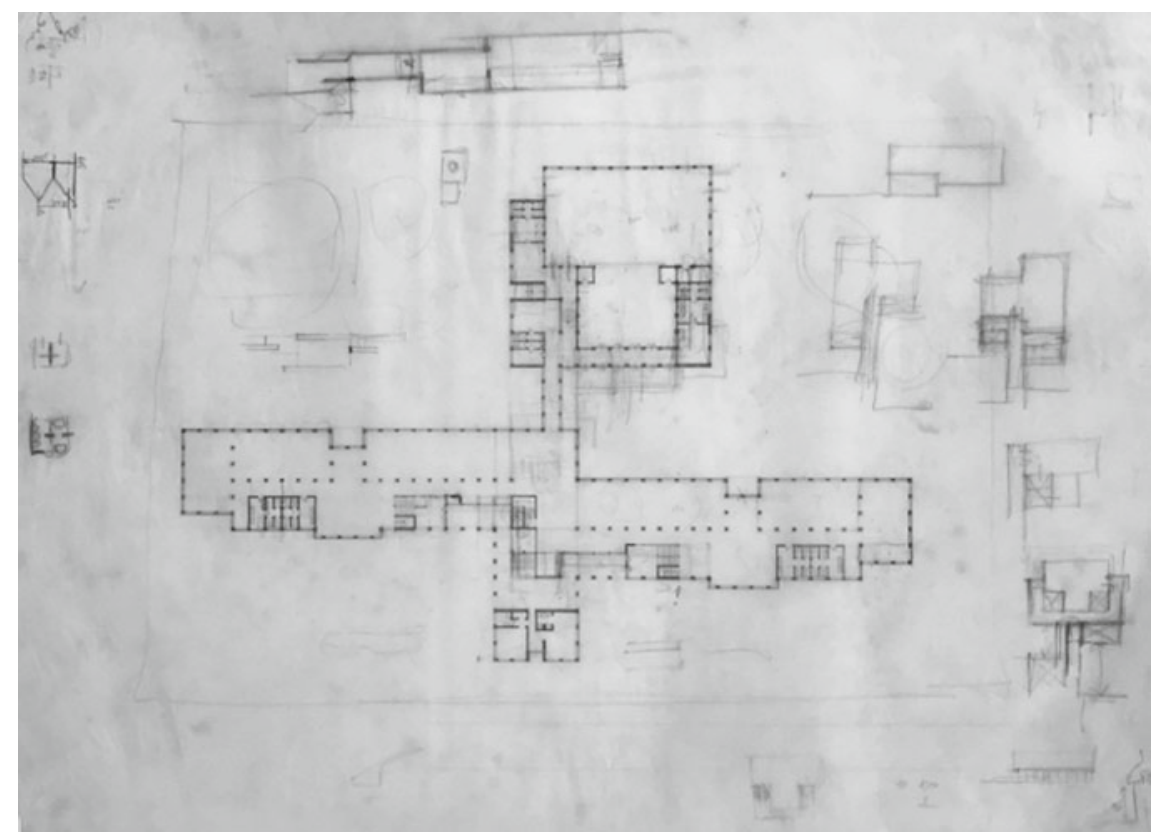

Fig. 5 Prefabricated Schools for the Municipality (Competition Contract), via Manin, Varese, 1965, Fondo Gardella, Coll. 68/3. Study Drawing, November 1965, Pencil on tracing paper. (CSAC, Sezione Progetto, Fondo I. Gardella, B001612P) 


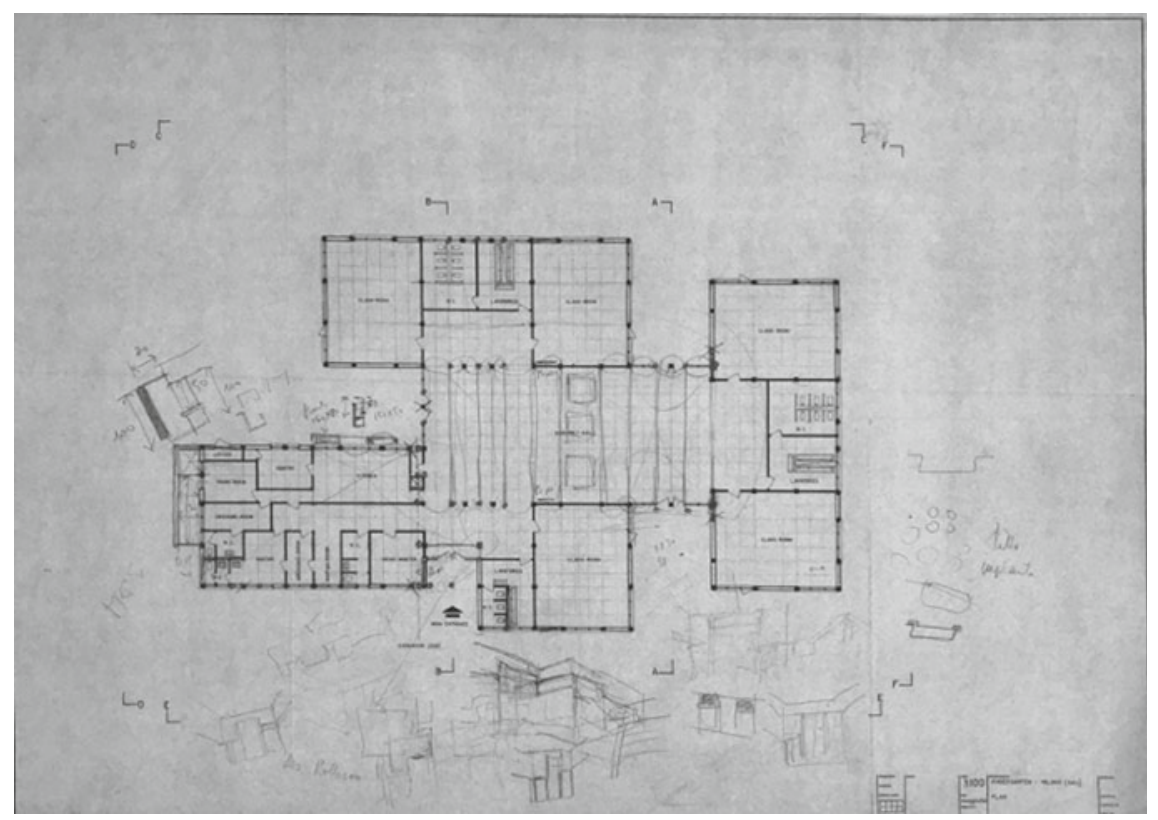

Fig. 6 Nursery School in Milan, Project, 1964, Study Drawing, Copy. (CSAC, Sezione Progetto, Fondo I. Gardella, B001601P)

\section{References}

Argan GC (1949) Il Museo come scuola. Comunità 3:64-66

Bodino C (ed) (1990) Arrigo Arrighetti

Bottoni P (1954) Antologia di edifici moderni in Milano. Editoriale Domus, Milano

Menghi R (2000) Roberto Menghi. Electa, Milano

Porta M (ed) (1985) L'architettura di Ignazio Gardella. Etas libri, Milano

Samonà A (1981) Ignazio Gardella e il professionismo italiano. Officina, Roma

Open Access This chapter is licensed under the terms of the Creative Commons Attribution 4.0 International License (http://creativecommons.org/licenses/by/4.0/), which permits use, sharing, adaptation, distribution and reproduction in any medium or format, as long as you give appropriate credit to the original author(s) and the source, provide a link to the Creative Commons license and indicate if changes were made.

The images or other third party material in this chapter are included in the chapter's Creative Commons license, unless indicated otherwise in a credit line to the material. If material is not included in the chapter's Creative Commons license and your intended use is not permitted by statutory regulation or exceeds the permitted use, you will need to obtain permission directly from the copyright holder.

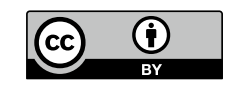

